\title{
LÍMITES Y LIMITACIONES DE LA HISTORIA: EL AFFAIRE AUBRAC
}

por

JUAN RAMÓN GOBERNA FALQUE

Escuela Española de Historia y Arqueología - CSIC (Roma).

RESUMEN: El 21 de junio de 1943 era detenido en Caluire, en la periferia de Lyon, Jean Moulin, el delegado de Charles de Gaulle en la Francia ocupada. Junto a él, fueron detenidos ocho responsables de la Resistencia de la zona sur, entre los que se enconträba Raymond Aubrac, miembro fundador del movimiento Libération-Sud, $y$, en ese momento, uno de los jefes de la Armée secrète, la organización militar de los movimientos de la Resistencia que Jean Moulin intentaba poner en marcha. Un bistoriador lionés, Gérard Chauyy, publicó en el mes de abril de 1997 una obra, Aubrac, Lyon 1943, en la que se analiza la presunta traición e implicación en los acontecimientos de Caluire de Raymond Aubrac y de su esposa, Lucie. Más allá del relato de las peripecias que vivieron los Aubrac durante el añ 1943, el autor se ba interesado por el affaire Aubrac porque es emblemático de las posturas que se entablan en la actualidad alrededor de la bistoria del tiempo presente, y que afectan al estatuto del testigo, al del bistoriador y a los usos ideologicos del pasado, por una parte, y porque muestra muy bien las dificiles y difusas relaciones entre la bistoria, la memoria, la justicia y los medios de comunicación, por otra.

Palabras Claviz: Teoria de la Historia. Lyon - 1943. Historia de la Resistencia francesa. Raymond Aubrac. Jean Moulin.

ABSTRACT: On June 21, 1943 Jean Moulin, Charles de Gaulle's delegate in occupied France, was taken prisoner in Caluire, on the outskirts of Lyon. Eight other members of the soutbern Resistance were arrested with bim, including Raymond Aubrac, founder of the Liberation-Sud movement and one of the then leaders of the Armée secrète - a military organization created to coordinate the actions tbat Jean Moulin was trying to carry out. A bistorian from Lyon, Gerard Chauvy, published a work called Aubrac, Lyon 1943 in April 1997, which analyzes Raymond Aubrac and bis wife Lacie's participation and alleged treason at Caluire. More than merely an account of the Aubracs' experiences in 1943, the author was interested in the Aubrat affair itself as an emblem of the current standpoints in regard to bistory at the present time -involving the status of the witness and the bistorian as well as the ideological use of the

Hi.pania, 1.:X/3, núm. 203 (1999) 1105-1127 
past- and as a way of showing the difficult and diffuse relationships between bistory, memory, justice, and the mass media.

KriY WORDS: Theory of History. Lyon - 1943. History of the French Resistance. Raymond Aubrac. Jean Moulin.

Paralelamente al proceso por crímenes contra la humanidad emprendido en Francia contra Maurice Papon, que ha supuesto el proceso implícito de la Francia de Vichy, ha tenido lugar el uproceso» a la Resistencia francesa durante la Segunda Guerra Mundial. En lo que a ésta se refiere, los medios de comunicación han focalizado desde siempre su interés casi exclusivamente en la detención en Caluire, en la periferia lionesa, el 21 de junio de 1943, de Jean Moulin, el delegado de Charles de Gaulle en la Francia ocupada, y de ocho tesponsables de la Resistencia de la zona sur, tras una operación de la sección IV del SipoSD de Lyon. Entre los detenidos se encontraba Raymond Aubrac, miembro fundador del movimiento Libération-Sud, y, en ese momento, uno de los jefes de la Armée secrète, la organización militar de los movimientos de la Resistencia que Jean Moulin intentaba poner en marcha 1.

Un historiador lionés, Gérard Chauvy, publicó en el mes de abril de 1997 una obra, Aubrac - Lyon 1943, en la que se analiza la presunta implicación en los acontecimientos de Caluire de Raymond Aubrac y de su esposa, Lucie ${ }^{2}$. Curiosamente, poco antes se había estrenado la película Lucie Aubrac, dirigida por Claude Berri, que narraba en clave hagiográfica las aventuras y desventuras de esta pareja durante los difíciles años de la Ocupación alemana, a partir de una adaptación de un libro autobiográfico de Lucie Aubrac titulado I/s partiront dans l'ivresse ${ }^{3}$.

Diecinueve personalidades de la Resistencia, en un documento de apoyo incondicional a los Aubrac publicado en el semanario L'Evenement du Jeudi $\left(n^{\circ} 648\right.$

1 Sobre la Resistencia francesa en generai, ver Henri Nogutires, Histoire de la Résistance en France, 5 vol., París, R. Laffont, 1967-1981; J.-P. AzÉMA, De Munich à la Libération, París, Le Seuil, 1987 (reed. 1997); J.-P. AzÉMA y F. BÉDARIDA, La France des années noires, 2 vol., Paris, Le Seuil, 1993; D. Cordiek, Jean Moulin. L'inconnu du Panthéon, París, J. Cl. LAtTìs, 1989; «La Résistance en 1943", Les Cabiers du l'IHTP, Éd du CNRS, junio de 1994. Sobre los movimientos de liberación, véase L. Douzou, La Désobéissante. Histoire du mowvement Libération-Sud, Paris, Odile Jacob, 1995; Dominique Veil.Jon, Le Franc-Tireur, Paris, Flammarion, 1977; Olivier WIEvionkA, Une certaine idée de la Résistance, París, Le Seuil, 1995. Sobre el papel de los partidos politicos, puede verse Marc SAdoun, Les Socialistes sous /Occupation, Paris, Presses de la Fondation Nationale des Sciences Politiques, 1982, y Stéphane CourroIs, Le PCF dans la guerre, París, Ramsay, 1980. En cuanto a las memorias de los resistentes, véase Claude Bourder, L'aventure incertaine, Paŕs, Stock, 1975; Henti FrEnAY, La nuit finira, París, Robert Lafont, 1973 (reed. 1989); Philippe VIANNAY, Du bon usage de la France, París, Ramsay, 1988; Serge Rnvnnes, Leeprit de la Résistance, París, Le Seuil, 1995.

2 Gérard Cilnuvy, Aubrac, Lyon 1943, París, Albin Michel, 1997.

3 Lucie AUBRAC, Ils partiront dans livresse, Paris, Le Seul, 1984 (reed. 1997). Esta película fue estrenada en España bajo el tíulo Amor en tiempos de guerra.

Hiiphania, LIX/3, núm. 203 (1999) 1105-1127 
del 3 al 9 de abril), se levantaron en un llamamiento público contra Gérard Chauvy y ulos bistoriadores o los que asi se consideram que «combaten la memoria de los muertos y al bonor de los supervivientes», para renegar asi de "esta estrategia de La sospecha, de la insinuación y del rumom. Pero la sombra de la traición permanecía en el ambiente. El antiguo secretario y biógrafo de Jean Moulin, Daniel Cordier rechazó firmar este llamamiento. Lo explicó en una larga entrevista, publicada en Libération el 8 de abril de 1997. Para él, y contrariamente a las insinuaciones de Gérard Chauvy, los esposos Aubrac no eran sospechosos de traición, especialmente en el affaire de Caluire. Pero, por el contrario, declaraba Daniel Cordier, «no pienso que los Aubrac bayan dicho, sobre el año 1943, toda la verdad [...] y desearía que se explicasen, no ante los tribunales, desde luego, sino frente a una comisión de bistoriadoress.

El libro de Gérard Chauvy seguía parcialmente la senda de las acusaciones de Klaus Barbie y de su abogado, Jacques Vergès, contra Raymond Aubrac, expuestas en un documento conocido como el «Testamento» de Barbie, y que Chauvy publica in extenso. La tesis que desarrollaba Jacques Vergès en este documento de 1990 era muy clara: Jean Moulin habría sido traicionado por unos jefes de la Resistencia, y en primer lugar por Raymond Aubrac. Este último podría corresponder al retrato del "V mann» (agente doble) descrito en el informe Kaltenbrunner (nombre del jefe de los servicios de seguridad del Reich) del 27 de mayo de 1943 como un "antiguo oficial francés» que ocupa «un puesto importante» en la Armée secrite. Y como en el informe no se desvelaba su identidad, la mención de este «Vmann» podía dar lugar a todo tipo de elucubraciones.

Raymond Aubrac había pedido, en vano, una comisión de historiadores, ya en 1991, cuando el «Testamento» de Barbie comenzaba a circular por las salas de redacción parisinas. En abril de 1997 resurge en la cabeza de Raymond Aubrac la idea de sugetir una smesa redondas. Finalmente, ésta se celebra en la sala de redacción del periódico Libération, el 17 de mayo de $1997^{4}$. Junto a los Aubrac, participaron Dominique Veillon, Jean-Pierre Azéma, François Bédarida y Henry Rousso, todos ellos historiadores del Institut d'bistoire du temps présent;

4 Las actas de la mesa redonda fueron publicadas integramente por el periódico Libération. el 9 de julio de 1997 en un cuadernillo especial de 24 páginas titulado «Les Aubrac et les historéns: le débats. Además, cada uno de los participantes publicó un articulo en Libération en torno a las conclusiones extraidas de la mesa tedonda: Raymond AUBRAC, "Ce que cette table ronde m'a apris»; Lucie Aubrac, «Des éloges aux soupçons» (10 de julio de 1997); Daniel CokDIER, «Je vous écris d'un pays lointain»; Dominique VEILLON, «Trouble-mémoire»; Henry Rous. so, «De l'usage du amythe nécessairem» (11 de julio); François BíDAridA, «Mémoire de la Résistance et devoir de vérité» (12-13 de julio), Jean-Pierre VERNANT, «Faut-il briser les idoles?»; Maurice AGULHON, «Un débat pénible bien peu productif); Laurent Douzou, «Les documents ne sont pas des électrons libres" (12-13 de julio); Jean-Pierre AzÉmA, “Affaire Aubrac: les faits sont têtus» (28 de agosto). El debate ha provocado reacciones controvertidas tanto en Libération como en Le Monde: véase Antoine Prosr; «Les historiens et les Aubrac: une question de trop", Le Monde, 12 de julio de 1997; Claire ANDrJEu y Diane DE BELLESCIZE, «Les Aubrac, jouets de l'histoire à l'estomao , Le Monde, 17 de julio; Gérard CinuvY, «Ma réponse au débat avec les $\mathrm{Au}$ brao, Libération, 24 de julio; VV. AA., (Déplorable leçon d'histoire), Libération, 25 de julio; Serge KlARsisild, à propos de Raymond Aubracs, Le Monde, 25 de julio.

Hipania, L.IX/3, núr 203 (1999) 1105-1127 
Maurice Agulhon, profesor en el Collège de France; Jean-Pierre Vernant, antiguo profesor del College de France y compañero de la Liberación; Laurent Douzou, autor de una tesis publicada bajo el título La Désobéissance, bistoire du mowvement Libération-Sud; y Daniel Cordier, el historiador de Jean Moulin.

Por aquellas fechas, además, los Aubrac ya habían denunciado por difamación a Gérard Chauvy. En el proceso, celebrado en febrero de 1998, reclamaban «justicia». El procurador Reygrobellet se esforzó en demostrar que, además de la reproducción del texto de 53 páginas firmado por Barbie, existian seis circunstancias de propósitos difamatorios. Si bien desechó la acusación de uffaurissonismon, el procurador consideró que las condiciones de la difamación upor insinuación, posiblemente por imprudenciay estaban bien definidas. Por fin, el 2 de abril de 1998 se hacía pública la sentencia: Gérard Chauvy y la editorial Albin Michel eran condenados a pagar una multa de $40000 \mathrm{~F}$ y $100000 \mathrm{~F}$, respectivamente, por «difamación pública» porque Chauvy había llegado «subrepticiamente a bacer plausible - a pesar de las reservas de forma del autor-la acusación de traición y de manipulación lanzada por la memoria Barbie (...) ). El tribunal había decidido condenar a Gérard Chauvy por «haber perdido de vista la responsabilidad social del bistoriador y haber faltado a las reglas esenciales del método bistóricom. En este sentido, «la publicación del señor Cbauyy se caracteriza por: un lugar excesivo concedido a la "memoria Barbie"; una insufficiencia de la documentación; una falta de jerarquización de las fuentes; un fallo de prudencia en la expresión; una falta de crítica interna de las fuentes y de los documentos alemanes; un abandono de los testimonios». Además, en concepto de daños y prejuicios, Gérard Chauvy y la editorial eran condenados a pagar a los Aubrac un total de $400000 \mathrm{~F}$.

Para aportar algo de luz a toda esta problemática, conviene, en primer lugar, hacer un relato aproximado de los acontecimientos del año 1943 que están puestos en tela de juicio: la primera detención de Raymond Aubrac ( 15 de marzo); la emboscada de Caluire (21 de junio); la estancia en la prisión de Montluc (julio-octubre); la evasión (21 de octubre).

\section{LAS PERIPECIAS DE RAYMOND Y LUCIE AUBRAC}

\section{La primera detenciôn de Raymond Aubrac}

La obra de Gérard Chauvy está construida sobre el esquema explicitado por Vergès-Barbie y que vincula la primera detención de Raymond Aubrac, el 15 de marzo de 1943, la segunda detención, en Caluire, el 21 de junio, y su evasión, el 21 de octubre. La mayoría de los historiadores especialistas en la historia de la Resistencia, entre ellos, Jean-Pierre Azéma, recusan esta tesis de la secuencia cronológicamente continua. Aunque los documentos publicados por Gérard Chauvy muestran el conjunto de contradicciones en las distintas declaraciones, explicaciones, versiones y variantes dadas al paso de los años por los esposos Aubrac, la emboscada de Caluire no podría explicarse directamente 
por la detención previa, en Lyon, en matzo de 1943, de una pequeña decena de responsables resistentes, tal y como sostienen Jacques Vergès y Klaus Barbie.

En efecto, Barbie afirma en su (testamentos que Raymond Aubrac habría empezado a colaborar con él desde el mes de marzo, después de su primera detención por unos policías franceses, detención seguida de un interrogatorio por unos hombres del SD. Pero nada prueba que el pseudónimo «Aubrac» ${ }^{5}$ haya sido entonces descubierto ni por los franceses ni sobre todo por los alemanes; y se puede comprender que el procurador concediese, el 10 de mayo, su puesta en libertad provisional, a pesar de la inculpación de umaquinaciones antinacionales», porque pudo pensar, en un primer momento al menos, que no se trataba más que de un simple agente de enlace. Lo que hace que la tesis de Vergès-Barbie, según la cual Raymond Aubrac habría sido liberado tras haberse comprometido a colaborar con la policín alemana «por miedo a morim, carece de fundamento.

El punto de partida son las detenciones realizadas en Lyon el 15 de marzo de 1943. La versión según la cual Raymond Aubrac habría sido detenido el 13 (y obligado a colaborar con los servicios de seguridad alemanes entre el 13 y el 15) se viene abajo inmediatamente en la medida en que todas estas detenciones de Lyon son consecutivas a una primera detención, la del agente de enlace Jean-Marie Curtil (portador de una lista de nombres) en la estación de Bourgen-Bresse, y que está datada con absoluta seguridad en la noche del sábado 13 al domingo 14 de marzo de 1943. Desde el momento en que se demuestra que Raymond Aubrac no fue detenido el 13, sino el 15 de marzo de 1943, toda el entramado argumental de Barbie-Vergès se viene abajo.

El «dossier Curtil» (ignorado por Gérard Chauvy en su libro), que ha sido encontrado en los archivos departamentales del Rhône, sirvió al abogado de Raymond Aubrac durante el proceso por difamación contra Gérard Chauvy, Georges Kiejman, para sostener que la fecha de la primera detención de su cliente fue el 15 de marzo de 1943: «No se encuentra nada en este dossier que permita pensar que Vallet [otro de los pseudónimos de Raymond Aubrac] baya sido detenido antes del 15 de marzo. Abora bien, para que éste baya sido "obligado a colaborar", tendria que baber sido detenido el 13 de marzos.

Todos los documentos franceses fechan la detención de Raymond Aubrac, Maurice Kriegel-Valrimont y Ravanel, asi como de numerosos camaradas, combinada de la incautación de una cantidad importante de documentos concernientes a la Armée secriete, el 15 de marzo de 1943. ¿Cómo y por qué se ha pasado de esta fecha segura del 15 de marzo a la del 13 de marzo, expuesta por Barbie por primera vez en su «Testamento»? Como ha puesto de manifiesto Daniel Cordier fue Gérard Hizard, quien en 1983 descubrió que esta fecha del 13 de marzo de la detención supuesta de Aubrac era la fecha contenida en el

5 La verdadera identidad de Raymond Aubrac es Raymond Samuel. Durante la clandesrinidad, ha utilizado varias identidades falsas, entre ellas Ermelin, François Vallet y Raymond Aubrac. Como muchos otros resistentes, después de la guerra Raymond Samuel tomó su pseudónimo más conocido, Raymond Aubrac, como nombre patronímico. 
informe Kaltenbrunner del 27 de mayo de 1943. Además, después de la Liberación, Aubrac (en una declaración de 1950, en el segundo proceso Hardy), Ravanel, así como el general Demasse se habían referido también esta fecha como la de su detención. Sin embargo, examinando el conjunto de los archivos franceses y alemanes actualmente disponibles, el informe Kaltenbrunner es el único documento que reproduce esta fecha. Con toda probabilidad fue retomada por Aubrac y sus camaradas después de haber tenido conocimiento de este texto después de la Liberación, porque debían haber olvidado la fecha exacta de los acontecimientos. Daniel Cordier está convencido de que se trata de un error de máquina y de que Aubrac y sus camaradas fueron detenidos por primera vez el 15 de marzo de 1943 en la calle de l'Hotel de Ville. Por el contrario, la observación de Hizard está probablemente en el origen de las acusaciones formuladas por Vergès en 1987 y por Barbie en 1990, dado que hasta esa fecha Barbie no había mencionado nunca el papel de Aubrac en el asunto de Caluire.

Raymond Aubrac había sido detenido por unos hechos vinculados directamente con la Resistencia. Considerado muy rápidamente por las autoridades francesa y alemanas como un «agente de enlaces, Raymond Aubrac fue objeto de una inculpación por "actos con el objetivo de perjudicar la defensa nacionab). Cuando Maurice Kriegel-Valrimont y Raymond Aubrac fueron interrogados por la policía alemana, hablaton de un asunto de tráfico de azúcar. La policía no creyó su coartada. Para la policía, François Vallet (uno de los pseudónimos habituales de Raymond Aubrac) pertenecía a la Resistencia, pero en un rango secundario, como pequeño agente de enlace. Este error habría permitido su puesta en libertad provisional el 10 de mayo.

Este asunto del mercado negro del azúcar supuso la primera acusación de «contradicción» a lo largo de la mesa redonda celebrada en la sala de redacción de Libération: Henry Rousso le reprochó entonces a Raymond Aubtac que haya contado en sus memorias, Où la mémoire s'attarde, publicadas en 1996, que había sido detenido por mercado negro ${ }^{6}$. En realidad, es una acusación inexacta, ya que Raymond Aubrac no ha declarado nunca en ninguno de los documentos reproducidos por Gérard Chauvy que hubiese sido detenido o inculpado por mercado negro. Era únicamente la explicación que él ofrecía para justificar su presencia en el local en donde se produjo la detención. Raymond Aubrac ha mantenido esta explicación ante los policías y ante el juez de instrucción. Y por ello, importa poco que en realidad no haya sido creído y que finalmente haya sido investigado por otras causas.

En la mesa tedonda también quedó claro que la puesta en libertad provisional de Raymond Aubrac estaba también vinculada a la acción del juez de instrucción Cohendy, que no quiso llevar las cosas más lejos, y no a la actitud amenazante de Lucie Aubrac durante una entrevista con el procurador Ducasse. En efecto, el juez Cohendy facilitó su puesta en libertad provisional, en tanto que la justicia francesa estaba convencida, en ese momento, de que no se

" Raymond Aubrac, Où la mémoire s'attarde, Paris, Odile Jacob, 1996.

Hiipania, LIX/3, núm 203 (1999) 1105-1127 
trataba más que de agentes de enlace y no de responsables de la Resistencia. Sin embargo, hay que precisar que en unos asuntos vinculados a la Resistencia, ni un procurador ni mucho menos un simple juez de instrucción tenían por sí solos la autoridad suficiente como para pronunciar una puesta en libertad provisional. Tenían obligatoriamente que informar de ello al fiscal general $\mathrm{y}$ al prefecto. Raymond Aubrac no es el único en beneficiarse de tal medida ya que otras tres personas (de las cuales dos eran agentes de enlace detenidos tras la captura del agente Curtil) fueron puestos en libertad provisional igualmente en aquel momento. Por tanto, estas otras puestas en libertad son resultado de un procedimiento judicial normal, y no de la intervención de Lucie Aubrac. Sin embargo, Lucie Aubrac mantiene su versión de los hechos. Según ella, se habría dirigido al procurador Ducasse en un tono muy amenazador: presentó a su marido como un «enviado de Charles de Gaulle», y le indicó que se atuviese a las consecuencias si le ocurría algo. Para autentificar su proceder en el nombre de la Resistencia, Lucie le habría informado de un mensaje que sería pasado a los pocos días por la BBC. Sin embargo, este mensaje ("Continuez de gravir les pentess), según Daniel Cordier, no pasó nunca. En cualquier caso, lo cierto es que este dossier, tras haber sido remitido a los alemanes, quienes dijeron que no les interesaba, volvió muy rápidamente a manos de la justicia francesa.

Para comprender un poco mejor todo este asunto, conviene deternerse un momento para explicar sumariamente cuál era la estrategia policial alemana en 1943 en lo que a la Resitencia francesa se refiere. Gracias a los informes enviados a Ribbentrop por Rudolf Schleier (que hace las veces, en primavera de 1943, de embajador del Reich en París), se sabe que los alemanes adquieren en ese momento la convicción de que un cierto número de ex-oficiales de la antigua Armée d'armistice se estaban organizando en su contra. Estas sospechas están justificadas, ya que es precisamente entonces cuando se comienza a organizar lo que se convertirá en la ORA, la Organisation de résistance de l'armée. Las autoridades de ocupación temen particularmente la acción clandestina de estos oficiales. Por este motivo, como indica un telegrama de Schleier, estaba programada para julio de 1943 una redada en estos medios militares, y que fue aplazada tras las detenciones de Caluire. El SD habia registrado el ascenso de los movimientos de resistencia en la zona sur. Los papeles incautados el 15 de marzo de 1943, en casa de Christine Denoyer, la compañera de Morin-Forestier, entonces jefe del estado mayor de la Armée secrìte, por la policía francesa y después transmitidos a las autoridades de la Ocupación han jugado un papel muy importante en la estrategia del SD. Los alemanes están seguros, desde entonces, de que al lado de los comunistas, al lado de los oficiales de la Armée d'armistice, había aparecido una tercera fuerza que podía practicar la lucha armada. Ahora bien, Kaltenbrunner, en el informe del 27 de mayo, subraya que esta Armée secrète, de la que él posee un organigrama casi perfecto, es tanto más peligrosa en cuanto que se corre el riesgo de que se alíe con los oficiales de la antigua Armée d'armistice: «Se puede constatar que ciertos circulos de oficiales se dedican a organizar unos grupos militares que en caso de invasión podrian cooperar con la Armée secritesy. Por eso el cerco de la Armée secrite se convierte en una de las tareas prio- 
ritarias de los servicios de seguridad del Reich en Francia: «El jefe de la Sicberbeitspolizei y del SD en París han sido llamados a prestar la mayor atención a la lucha contra la Armée secrètè. Es en el marco de esta acción prioritaria que los alemanes logratán la colaboración del secretario de Chevance-Bertin (un responsable del movimiento Combat), Jean Multon, llamado Lunel, detenido el 28 de abril, y que provocará directa o indirectamente de la caída de cerca de 120 tesistentes y permitirá al Sipo-SD llegar de golpe hasta la cabeza de la Armée secrète.

Dicho esto, se comprende perfectamente que en aquel momento era evidentemente esencial que ni los franceses ni los alemanes descubriesen que el tal Vallet era en realidad Raymond Aubrac. Está claro que, por una parte, se incautan unos archivos de extrema importancia y, por otra parte, se ha detenido a unas personas que están mencionadas en estos archivos, pero en ese momento no se estableció un vínculo entre los dos sucesos. Laurent Douzou expresó durante la mesa redonda su convicción de que esto fue debido a que era muy difícil comprender en aquel preciso momento la importancia de las detenciones que habían realizado.

El procurador Ducasse, por su parte, en su informe fechado oficialmente el 30 de marzo de 1943, también menciona de manera explícita estos documentos. Es un informe muy detallado sobre las detenciones operadas el 15 de marzo. Será incluso transmitido a la Chancellerie. Para Ducasse, por tanto, se trata de un asunto importante porque únicamente los dossieres que presentaban una cierta envergadura política o judicial eran transmitidos a la Cbancellerie, para información y para instrucciones. Por otra parte, gracias a una investigación llevada a cabo en los archivos por Henry Rousso, se sabe que este dossier también fue transmitido por el ministro de Justicia al secretariado de Estado en la Guerra.

Además, otros documentos revelan que el asunto del 15 de marzo de 1943 fue juzgado inmediatamente de gran importancia, tanto por Vichy como por los alemanes. Daniel Cordier, durante la mesa redonda, presentó una circular dirigida a todos los comisarios de policía por Buffet, director de los servicios de policía, fechada el 24 de marzo (o sea, nueve días después de las detenciones): «Tengo el bonor de dirigirles bajo este pliegue, para información, la copia de una nota establecida el 22 de marzo de 1943 por un funcionario de mi dirección en torno a la Armée secrite y de sus vínculos con los movimientos unidos. Les ruego intensifiguen sus investigaciones en vista a identificar y detener a los representantes de esta organización en muestra region $y$ de bacer llegar con extrema urgencia toda información que ustedes puedan poseer o recoger al respecto de este movimiento sedicioso que representa un grave problema para el orden y la seguridad pública".

René Fallas, antiguo miembro del comité director del movimiento de Liberación nacional, autor del prefacio del libro de Gérard Chauvy, declaró a su favor en el proceso por difamación emprendido contra él por los Aubrac. René Fallas evocó durante este juicio un mensaje telefónico fechado el 26 de marzo y recibido en Vichy que probaría, según él, que las policías francesa y alemana estaban perfectamente al corriente de la importancia de las detenciones efectuadas en Lyon el 15 de marzo de 1943: "El SD sabe que se trata de un astnto muy

Hipunia, LIX/3, num. 203 (1999) 1105-1127 
importante. Pero los alemanes y los franceses practican la táctica de la cuerda larga. Dejan correr a sus prisioneros para atrapar a los dirigentess.

A esta versión, Maurice Kriegel-Valrimont opuso, en este juicio por difamación, su propio testimonio: «Nosotros bemos sido remitidos a los alemanes en el botel Terminus. Habia un grupo de SS que se consultaban y se preguntaban si valiamos la pena. Como be nacido en Estrasburgo en 1914, el alemán me es familiar, y be comprendido que ellos decian que no era asunto para su nively nos ban devuelto a casas. Para Maurice Kriegel-Valrimont, en marzo de 1943, la policía alemana no comprendió apenas la importancia de las detenciones, tanto que ni siquiera intertogaron a otra de las víctimas de la redada, François Morin-Forestier, el adjunto del general Delestraint, jefe de la Armée secrète, y por tanto, superior de Raymond Aubrac.

En cualquier caso, como reconoce Henty Rousso, wes cierlamente extraño, cuando se examina este asunto después, ver que los magistrados franceses detienen a unos agentes de enlace, incluso considerados como unas comparsas, que hacen el vinculo con los papeles Morin-Forestier que conciernen a un asunto muy importante (la Armée secrète) y que, a pesar de todo, Les ponen en libertad provisional. Pero el historiador no tiene el derecho, en el estado de la documentación, de ir más allá, y de pretender que, ya que es "sorprendente", esto sería "sospechoso". Cuando se trabaja sobre este periodo, se descubren cosas bastante más sorprendentes auim.

\section{Caluire, 21 de junio de 1943}

La historiografía clásica sobre los acontecimientos de Caluire tiende a reducir la cuestión que plantea este episodio a la hipótesis de la traición por parte de René Hardy, uno de los dirigentes de la Resistencia. Sin embargo, para analizar lo que ha podido ocurrir en Caluire, habría que tener en cuenta a la vez la estrategia policial del ocupante y las repercusiones de las diferentes políticas que oponen a Jean Moulin y un cierto número de responsables de los movimientos de Resistencia. Sobre el primer punto, ya hemos visto la importancia fundamental concedida a la emergencia de la Armée secrète en Francia, como destaca Kaltenbrunner en su informe del 27 de mayo. Por lo que se refiere al segundo punto, hay que tener en cuenta que, a pesar del éxito que había constituido la formación del Conseil national de la Résistance (CNR) reunido en París por primera vez el 27 de mayo bajo la presidencia de Jean Moulin, fue también entonces cuando los desacuerdos, las rivalidades y las tensiones alcanzaron su punto culminante. Ásperos conflictos oponen en particular a los jefes del movimiento, Henri Frenay por Combat y Emmanuel d'Astier de La Vigerie por $L i$ bération, al enviado del general de Gaulle. Moulin era criticado porque, en tanto que delegado general del jefe de la Francia libre, se limitaba a aplicar las directivas «de Londres».

Ahora bien, si a los ojos de Charles de Gaulle los resistentes del interior debían considerarse a sí mismos como soldados a sus órdenes, para un gran número de jefes de movimientos, que reivindicaban su autonomía política, la obediencia a Londres no era debida más que a una serie de directrices específi- 
camente militares. Además, estos responsables reprochaban a Moulin su autoritarismo. En esta primavera de 1943 intentan yugular la importancia creciente que ha tomado el patrón de la Délégation générale quien pasa a ser también, a partir de mayo, el presidente del CNR y el del Comité director de los MUR. Esto planteaba un verdadero problema a los jefes de movimiento. Por consiguiente, no es extraño en este contexto que se produjese una especie de unión sagrada de los movimientos contra lo que consideran como una expropiación excesiva del poder. Sin embargo, como destaca Laurent Douzou, «es muy dificil ponerla en tela de juicio, ya que Jean Moulin, de una cierta manera, se ba convertido en uno de los suyos porque ba edificado esta unidad con ellos. (...) Su legitimidad es, por tanto, totabs. Daniel Cordier matiza esta afirmación insistiendo en el hecho de que esta legitimidad ya no estaba reconocida en esta época por los jefes de movimiento, porque no se debe olvidar que d'Astier y Jean-Pierte Lévy habían partido hacia Londres el 17 de abril de 1943 con el objetivo de hacer despedir a Delestraint y Moulin, y que ante las dificultades encontradas en Londres, esperaban a Frenay para conducir el asalto decisivo.

En esta atmósfera de crisis, en medio de los desastres que golpean a los combatientes clandestinos (las detenciones del 15 de marzo en Lyon, la redada masiva en Marsella tras la traición de Lunel, la detención en París el 9 de junio del general Delestraint, jefe de la Armée secrète...), se impone la toma de importantes decisiones. De ahí la reunión prevista por Jean Moulin en Caluire.

Los responsables de los movimientos de la zona sur, entre ellos su jefe, Henri Frenay, reprochan a Moulin la penuria de medios así como la reintroducción de los partidos políticos, a instancias de Charles de Gaulle, en detrimento de los movimientos, en el futuro Conseil National de la Résistance. Jean Moulin, por su parte, consideró como falta muy grave el intento hecho por Henri Frenay de esquivar a la France libre y a su delegado general proponiendo a los servicios secretos americanos, instalados en Suiza, la entrega de informaciones a cambio de dinero y medios de radio. Este tema es conocido como el affaire suizo. Según Daniel Cordier, todos los jefes de los movimientos deseaban obtener una ayuda material directa de los americanos a fin de ser independientes de la Francia libre. Lo que les chocaba en este asunto es que Frenay hubiese negociado tanto a sus espaldas como a las de De Gaulle y de Moulin durante más de un mes. En cualquiex caso, el propio Raymond Aubrac reconoce haber comprendido los tratos de Frenay para que la Resistencia pudiese disponer de los recursos económicos que le faltaban.

François Bédarida planteó otra cuestión a lo largo de la mesa redonda, en relación con los acontecimientos de Caluire. Dadas, por una parte, las relaciones entonces muy tensas entre Libération y Combat, por otra parte, la posición de árbitro de Jean Moulin al frente de los MUR, ¿cómo se podría explicar que éste le haya dicho a Raymond Aubrac que le escogia a él para dirigir la Armée secrète en la zona Norte y que al mismo tiempo nombrase a André Lassagne responsable de la zona Sur, con lo que se ofrecía a Libération la ditección de la Armée secrète en las dos zonas, en detrimento de Combat,

Hippania, LIX/3, núm. 203 (1999) 1105-1127 
cuyas ambiciones etan sin embargo muy patentes? Lógicamente, Raymond Aubrac responde con un lacónico «no sés, y se limita a especular con la posibilidad de que Jean Moulin sufriese «una reacción de distancia respecto a los bombres de Combat en aguel momentos.

Otra de las "explicaciones» solicitadas a Raymond Aubrac en función de las contradicciones entre varios testimonios concierne a la elección del lugar de la reunión de Caluire. François Bédarida asegura que Lassagne y Aubry han declarado que la fecha, la hora y el lugar de la reunión, la casa del Dr. Dugoujon, habría sido elegida concertadamente con Raymond Aubrac durante la reunión del 19 de junio en casa de Lonjaret. Por su parte, Raymond Aubrac ha sostenido regularmente (en esto no ha variado sus declaraciones) no haber sabido el lugar de la cita más que dirigiéndose hacia allí con Jean Moulin el lunes 21 de junio por la tarde, después de haber encontrado a este último en la plaza Carnot. El lugar habría sido fijado en la hora de la comida, el domingo 20 de junio, cuando André Lassagne se fue a casa de Dugoujon y le preguntó si podian mantener una reunión al día siguiente en su casa. Raymond Aubrac añade que ni siquiera Jean Moulin, cuando el domingo por la tarde le fijó una cita para el lunes por la tarde, conocía en ese momento el lugar de la reunión; si no, no le habría citado en la otra punta de Lyon. Lo cierto es que el propio Gérard Chauvy, que busca en las declaraciones divergentes de Lassagne sobre esta cuestión, se limita tan sólo a insinuar (pero sin llegar a ninguna conclusión definitiva) que Raymond Aubrac habría conocido el lugar de la reunión el 19 de junio.

Raymond Aubrac rememora la conversación que tuvo con Jean Moulin la víspera de Caluire, el 20 de junio de 1943, en el parque de la Tête d'Or. Según Aubrac, Jean Moulin decía claramente que se trataba únicamente de tomar una serie de disposiciones transitorias y de ningún modo de nombrar al sucesor del general Delestraint. Aubrac habría aceptado como misión continuar las negociaciones que habían comenzado Delestraint en la zona Norte. En todo caso, parece claro que Combat también reivindica una posición importante en la $A r$ mée secrìte y, por otra parte, que Frenay habría querido ser el jefe de la Armée secrète tras la detención de Delestraint.

Con este trasfondo de tensión se produce el affaire Hardy. René Hardy, el jefe de la red NAP-Fer, había sido reclutado seis meses antes por Combat, y se había convertido en el responsable de la penetración por la Resistencia de la administración de la SNCF. Caido algunos días antes de los acontecimiento de Caluire en manos de la Gestapo, no había sido convocado a la reunión pero, contraviniendo todas las consignas de seguridad, fue enviado alli, al parecer, para apoyar al otro responsable de Combat, Henri Aubry, poco capacitado para una reunión cuyo objeto era, o al menos eso pensaban, ocuparse del remplazo del jefe de la Armée secrète, el general Delestraint. René Hardy fue absuelto dos veces (en enero de 1947 y en mayo de 1950) de la inculpación de haber informado a los alemanes de la reunión de Caluire. Sin tener por nula la cosa juzga$\mathrm{da}$, un buen número de historiadores, apoyándose especialmente sobre dos informes alemanes contemporáneos (un segundo informe Kaltenbrunner del 
29 de junio de 1943 y el informe Flora fechado el 19 de julio) ${ }^{7}$ que indican de la manera más formal que René Hardy habría colaborado con el Sipo-SD, consideran que Hardy fue quien condujo de hecho a los hombres del SD, y por tanto a Barbie, a la reunión de Caluire. Su sospechosa huida, durante la redada, no hace más que añadir verosimilitud a la hipótesis de su traición.

Raymond Aubrac apoya esta versión de la traición de Hardy: «Desgraciadamente sigo estando convencido de que el responsable fue René Hardyy. Desde 1948, y hasta los años 80, Klaus Barbie había designado a René Hardy como único responsable. Georges Kiejman, el abogado de los Aubrac durante el proceso por difamación contra Gérard Chauvy, mostró una carta con fecha del 1 de enero de 1983 que Barbie, desde su prisión boliviana, había enviado al realizador Claude $\mathrm{Bal}$, que preparaba un documental inspirado por Jacques Vergès (Que la térité est amired. «1) Hardy no ba sido mi agente. Detenido por la aduana y la policía alemana, ha aceptado el trato gue yo le proponia con el acuerdo de mis jefes: la libertad contra Max Dean Moulin]. 2) Este acuerdo babia sido condicionado por él al acuerdo de sus jefes. Desde el día siguiente de su puesta en libertad bajo vigilancia, ba obtenido el acuerdo del general de Bénouville [responsable del movimiento Combat] (...) 3) La base politica de este acuerdo era una voluntad común de luchar contra el peligro comunista». Curioso argumento: la evocación de este documento había valido en 1987 a Claude Bal y a Jacques Vergès una condena por difamación hacia los esposos Aubrac y Pierre Guillain de Bénouville (Le Monde del 2 de noviembre de 1985 y del 4 de mayo de 1987).

\section{La prisión de Montluc}

La primeta cuestión: ¿quién identificó a Jean Moulin? Parece que fue otro de los detenidos, Henri Aubry quien teveló a los alemanes que el que decía llamarse Martel era en realidad Max, el pseudónimo de Jean Moulin. Y que el que decía llamarse Ermelin o Vallet, era Raymond Aubrac. Durante la mesa redonda, Raymond Aubrac relató este acontecimiento del siguiente modo: «En el patio, [Aubry] me dijo: "He bablado". No me dijo que bubiese designado a fulanito o menganito. Fui interrogado a continuación por Barbie sobre la base de las declaraciones que babía becho Aubry. La probabilidad más factible es que fuese él quien designó a "Max", pero probablemente no enseguida. Han debido necesitar 24 o 48 boras. No sé nada de ello. También pienso que fue él quien dijo que yo era Aubrac. Sin embargo, no tengo pruebass.

Daniel Cordier fecha la identificación de Aubrac, por parte de Barbie, a partir de del informe del comisario Porte, mencionado por Chauvy (quien no indica sin embargo su autor). En este documento remitido a Londres el 27 de julio de 1943, Porte escribe: "Hemos sabido por la señora Aubrac que antes del interrogatorio del lunes 21 [error de máquina, hay que leer lunes 28], su marido y Max [Jean Moulin] babrian sido detenidos como simples clientes del doctor. Pero, después de este

7 El informe Flora es un balance establecido por el Sipo-SD de la región de Marsella de las detenciones provocadas por la colaboración y traición del antiguo resistente Jean Multon, llamado Lunel.

Ilipania, LIX/3, núm 203 (1999) 1105-1127 
interrogatorio, debia ser considerado como un jefe principal de la $A S$. Resultado de zna entrevista muy rápida entre ella [la señora Aubrac] y su marido en la prisión. [Esta formulación poco explícita confirma que es después del segundo interrogatorio de Aubrac cuando Barbie ha descubierto su identidad de Aubrac y su papel]. La segunda parte de esta información es debida a una entrevista entre la señora Aubrac con el jefe de la Gestapo, (Berbiv) [Barbie]».

Las contradicciones en torno a la identificación de Aubrac, tras ser detenido en Caluire, provocaron en el transcurso de la mesa redonda una dura polémica. Henry Rousso declaró que «el primero en poner en evidencia las contradicciones en las declaraciones sucesivas [de Raymond Aubrac] después de Caluire no ba sido un bistoriador ni un periodista en búsqueda de scoop, sino un juez de instrucción». El juez de instrucción del que se habla es Jacques Hamy, encargado de la instrucción en el segundo proceso contra Barbie, quien intertogó a Raymond Aubrac en 1992, a petición propia, después de que el documento Vergès-Barbie, remitido al juez algunos meses antes, hubiese circulado en las salas de redacción parisinas. Desconcertado, Raymond Aubrac sólo pudo contestar: «Señor Rousso, tiene usted razón. He divergido por unas raqones que se me escapan». Sucesivamente, Cordier, Bédarida, Rousso e incluso Azéma subrayaron las consecuencias dramáticas de estas contradicciones que, según ellos, ocultaban algo grave, inconfesable.

Daniel Cordier ha diseccionado todas las declaraciones de Raymond Aubrac en torno a su identificación. Cuando Raymond Aubrac llega a Londres en 1944, le cuenta al servicio de contraespionaje del BCRA que los alemanes le han identificado como Aubrac, uno de los jefes de la Armée secrète: "Ahora bien, estaba obligado a reconocer que era Aubrac cuando ellos me identificaron como Vallet, ya que ellos sabian que Vallet y Aubrac no eran más que una misma y única personats. En Argel, cuatro meses más tarde, recordando el mismo episodio, dice: «los alemanes admitieron como verdadera identidad la de François Vallet. Füe así como continué existiendo todo el tiempo bajo el nombre de Frangois Vallets. Como ninguna otra pregunta le fue planteada, Raymond no tenía por qué decir más, omitiendo añadir que los alemanés sabían que Vallet era Aubrac y, por consiguiente, que le habian reconocido en tanto que un responsable de la Armée secrite. En París, el 18 de abril de 1948, en el transcurso del segundo proceso Hardy, Raymond Aubrac repite su primera declaración en Londres en 1944: ipude constatar que los alemanes conocian en lo que me concierne personalmente, no sólo mi verdadera identidad sino, por una parte, la identidad de Ermelin y de Vallet, nombres bajo los cuales yo babia sido detenido y puesto en libertad por la policia francesa; y por otra parte, el hecbo de que yo era Aubrac y cual era más o menos mi actividads. El 2 de mayo de 1950, en el transcurso del mismo proceso, respondiendo a las preguntas de M. Garçon, confirma esta versión: «- ¿ Sabian ellos quiét era usted? - No enseguida. - _Por consiguiente, ocho días después, los alemanes...-: Debo decir, señor, que no sé lo qué sabían los alemanes. Sé que ellos (no) me ban dicho que yo era Aubrac más que el segundo o de tercer día...n. En 1983, ante una comisión rogatoria en el affaire Barbie, declara como en Argel: «Fui interrogado personalmente por Barbie que me reconoció en tanto que Franfois Vallet). De nuevo, no dice ni pío de la identificación Vallet-Aubrac. Sin embargo, en 1992, ante el juez Hamy, vuelve a la versión integral de Londres. "Ahora bien, fui obligado a reconocer

Ihíptaniu, L.LX/3, núm. 203 (1999) 1105-1127 
que yo era Aubrac cuando me identificaron como Vallet ya que sabian que Vallet y Aubrac eran una misma y única persona», y añade: "(...) Los alemanes admitieron por verdadera identidad la de Frangois Vallets. Por el contrario, en 1996, en su libro de memorias, Où la memoire s'attarde, Raymond Aubrac escribe: «Si Barbie babia descubierto que Ermelin era en realidad Vallet, no habia ido más allá de esta interpretación bastante parcial. No me babia desnudado para constatar que yo podia ser perfectamente judion. Daniel Cordier confiesa que la lectura de estas páginas le ha dejado perplejo porque si olvida, como en Argel, indicar que Barbie sabía que Vallet era Aubrac, por el contrario, Raymond escribe una frase incongruente cuando se conocen sus declataciones anteriores: "(...) Yo temia gue mi verdadero papel bubiese sido descubierto, mi identidad reconocida. Entonces, todo estaria perdido». Hasta la escritura de Où la mémoire s'attarde, no se podría decir que hubiese contradicciones ya que habría solamente omisión. Por el contrario, es evidente la contradicción que existe entre todas sus declaraciones y la afirmación contenida en sus Memorias.

Henry Rousso aporta también una cita del libro de Lucie Aubrac, Ils partiront dans livresse: «Raymond Aubrac babia sido detenido en Caluire el 21 de junio de 1943 al mismo tiempo que Jean Moulin. Los alemanes ignoraban su identidad real, Raymond Samuel, el becho de que él era judio, y gue su nombre de Resistencia era Aubrac. Ellos le conocian bajo el nombre de Ermelin». A partir de esta cita, Rousso concluye: «Nosotros sabemos hoy, gracias al propio Raymond Aubrac, que una parte al menos de esta aserción es falsa: los alemanes le babian identificado como "Aubrac", y por definición, ni él, ni su esposa, podian ignorarlos.

Como ocurría en el asunto de la primera detención, la del 15 de marzo de 1943, dependiendo de que Raymond Aubrac haya sido o no identificado, todo cambia. Porque si se trata de François Vallet, es verdaderamente un asunto de escasa importancia: no es más que un modesto agente de enlace de la Resistencia. Por el contrario, como dice François Bédarida, a partir del momento en que Raymond es identificado como Aubrac, «se convierte en caza mayom. Es precisamente bajo el pseudónimo de Aubrac como está fichado el jefe adjunto de la Armée secrìte. Desde finales del año 1942 es el nombre bajo el que Raymond trabaja en la Resistencia, como se deduce de los telegramas enviados a Londres para relatar sus tratos con el general Frère y con el general Revers y sus negociaciones sobre la entrega de armas de la Armée d'armistice. Es el nombre que figura en los documentos incautados en Lyon el 15 de marzo de 1943. El servicio de información alemán se burla absolutamente de los pseudónimos de Ermelin o de Vallet bajo los cuales Raymond disimula su verdadero papel.

La sospecha recae también sobre los motivos de la permanencia en Lyon de Raymond Aubrac tras su detención en Caluire. En buena lógica, Raymond Aubrac habría debido ser transferido a París, como el resto de sus camaradas (salvo Larat). Después de algunos días de interrogatorios, y algunas semanas encarcelado, se le ha notificado a Aubrac una condena a muerte «pronuniciada en Parín, después se le ha vuelto a meter en la celda de Montluc. Según Serge Klarsfeld, en Le Monde del 25 de julio de 1997, la Gestapo de París estaría muy ocupada tras la detención en París, el 24 y el 25 de junio, de miembros de una red de información, la red «Prospen, lo que explicaría el «desinterés de la Gestapo en cuanto al traslado de Ray- 
mond Aubrac». Serge Klarsfeld se apoya sobre el testimonio de un responsable de la Gestapo parisina, Ernst Misselwitz, interrogado por los servicios franceses el 7 de julio de 1947. Sin embargo, como destaca Jean-Pierre Azéma, los informes Kaltenbrunner del 27 de mayo y del 29 de junio, así como el informe Flora del 17 de julio, confirman que las detenciones de Caluire no fueron tratadas en ningún momento como un asunto mediocre.

En todo caso, ya que fue mantenido en Lyon, habría debido ser interrogado sin muchos miramientos por Barbie, antes de ser o fusilado o deportado como «Nacbt und Nebel»" Sin embargo, permaneció encarcelado en Lyon, sin ser torturado, aunque sobre este punto preciso también es posible que la muerte de Jean Moulin, que le fue reprochada a Barbie por sus superiores, haya beneficiado a $\mathrm{Er}$ melin-Aubrac. $Y$ en todo caso, es evidentemente extraño que, al interrogatle tan sólo cinco o seis veces en cuatro meses, Barbie se haya contentado con una parte bastante escasa de las informaciones que podría sonsacar a Raymond Aubrac. En este sentido, Raymond Aubrac se defiende una vez más diciendo que «existen, en toda mi bistoria, unas preguntas a las que yo no puedo responden.

Pot lo que se refiere a Lucie Aubrac, parece sospechosa la gran cantidad de visitas que realiza a la sede de la Gestapo durante el periodo en prisión de Raymond Aubrac. Según las fechas dadas en Ils partiront dans liviresse, realizó dos visitas a Barbie (el 23 de junio, la primera, y el 28 de junio, la segunda). A continuación, inició conversaciones con el coronel Krieger (oficial superior alemán, encargado de los servicios económicos en Lyon). La primera visita habría tenido lugar el 17 de agosto, la segunda el 24 de agosto, la tercera el 30 de agosto y la cuarta el 8 de septiembre. El 10 de septiembre, un tercer personaje aparece: el aspirante a SS Lutgens, miembro del Kommando de la Gestapo en la Ecole de santé militaire, en el servicio de Barbie. Habría vuelto a verle el 14 de septiembre, el 21 de septiembre, y después el 28 de septiembre. El 14 de octubre Lucie habría realizado una visita a la vez al coronel Krieger y al aspirante Lutgens. Por fin, el 21 de octubre habría tenido lugar la sexta y última entrevista con Lutgens. Doce visitas, de las cuales Lucie sólo da como seguras las dos con Barbie: «Yo no garantizo las fechas. Yo no be escrito un libro de bistoriadoras. Por otra parte, Lucie ha asegurado que durante sus visitas a la sede de la Gestapo nunca se le pidió el documento de identidad. Todo esto es realmente difícil de creer, teniendo en cuenta que fue en 1943 cuando el Reich entró de lleno en la guerra total y cuando las autoridades de ocupación multiplicaron las precauciones, especialmente contra los atentados. Y como el SD de Marsella y de Lyon acababan de hacer caer a 120 resistentes, esta ausencia de control ciertamente es sorprendente. Y esta sorpresa alimenta la sospecha y la duda.

También puede parecer extraño que la policía alemana no haya intentado aprovecharse de las visitas de Lucie Aubrac, por ejemplo, llevando a cabo unos seguimientos policiales. Fue Daniel Cordier quien planteó esa hipótesis a lo largo de la mesa tedonda: «La policia alemana estaba en condiciones igualmente de seguiros

8 La ordenarza del 12 de diciembre de 1941 condenaba a los deportados «Nacht und $\mathrm{Ne}$ bels a una desaparición sin huellas. 
y de vigilaros. En esta medida, las idas y venidas de Lucie a la Gestapo zno ban incitado a la Gestapo a seguirla? (...) Comprendiendo la importancia de tu papel en la Armée secrète, los alemanes entonces te babrian mantenido en Lyon, para, gracias a un dispositivo de vigilancia apropiado, poder efectuar un vasta redadas. Esta hipótesis provocó la reacción indignada de Raymond Aubrac, quien respondió: «Dicho de otro modo, tu vas un poco más lejos que Vergès. En todo caso, ninguna redada se produjo a continuación.

Sin embargo, el hecho de que inmediatamente después de la evasión de Raymond Aubrac el Sipo-SD pueda tender una trampa en la villa en donde los esposos Aubrac eran conocidos bajo su verdadera identidad, la de Samuel, podría indicar que ésta había sido descubierta con anterioridad. Teniendo en cuenta que Samuel es un apellido judío, surge otra serie de preguntas sin resolver sobre el trato «excepcional» recibido por Raymond Aubrac durante su estancia en prisión. ¿Conocían su verdadera identidad?, jo la descubrieron después de su evasión? Según los Aubrac, existen tres posibilidades: puede que la casa de los Aubrac-Samuel haya sido localizada porque la Milicia había comenzado a delatar a los judíos que estaban todavía en libertad en Lyon; puede que la Gestapo haya ido en primer lugar al instituto en el que trabajaba Lucie para pedir sus fotos de identidad, a fin de reconocerla y de tener su dirección; $o$, por último, teniendo en cuenta que los hombres del equipo de Lucie que lograron la evasión del 21 de octubre se habían llevado consigo a una decena de detenidos a los que fueron abandonando poco a poco en el monte, puede que la Gestapo haya podido interrogarles a continuación.

Otra de las dudas planteadas por Gérard Chauvy en su libro se refiere a la posibilidad de que en realidad la evasión del 21 de octubre hubiese sido preparada para otro detenido, Jean Biche, y que Raymond Aubrac no hubiese sido más que un beneficiario. Raymond Aubrac ha presentado como documento el testimonio del coronel Dupuy, quien en una carta confiesa: «Yo era, en aquel momento, el responsable regional de la red Nilo, la de Jean Biche. Jean Bicbe era mi camarada. Fue deportado. Le volvi a ver a menudo después de su retorno de la deportación y nunca me bablo de un intento de evasión del cual él babria sido beneficiarios. El propio François Bédarida niega la credibilidad a esta hipótesis: «Ninguno de los presentes ba concedido nunca la menor credibilidad a esta versión rocambolesca que no se tiene en pie. Añado, en la medida en la que el llamado Biche se vale de lazos con Temoignage chrétien y con el padre Cbaillet, que el personaje parece muy poco creibles.

Por último, Daniel Cordier formuló por primera vez la hipótesis según la cual Lucie y Raymond tendrían una responsabilidad (indirecta) en la muerte de los padres de Raymond. Para ello se basa en la imprudencia de Lucie al haber enviado a su cuñada a buscar ropa limpia a la casa de los Aubrac-Samuel cuando ésta ya estaba siendo vigilada por los alemanes. Raymond Aubrac explica la detención de sus padres, tres meses después de este incidente, de otra manera: hacia finales de noviembre de 1943, uno de sus primos hermanos, Paul, habría sido reconocido en la calle por uno de sus antiguos camaradas de universidad convertido en miliciano. Tras ser detenido por la Milice y entregado a la Gestapo, los alemanes acabarían deteniendo a los padres, a la tía y a la prima de Ray-

Hiphuin, LIX/3, súm. 203 (1999) 1105-1127 
mond. Los llevaron a Drancy. Después, sus padres fueron llevados a Auschwitz $\mathrm{y}$ asesinados a su llegada, sin haber sufrido nunca ni un solo interrogatorio. Para Daniel Cordier, wbay que demostrarlo. El becho de haber enviado a alguien a la avenida Esquirol [dirección de la casa de los Samuel-Aubrac] pudo entrañar la detención de tu familia. Es una bipotesis. (...) En el fondo, tu no eres ni responsable ni culpable de este acontecimiento, pero algo atroz resulto de ello: la consecuencia de baber enviado a tu bermana alli en donde se encontraba la Gestapo sería la muerte de tu familia. Esto puede pesar toda una vida sobre la consciencia de un bombre, incluso si tu no eres culpables.

Hasta aquí el relato de las peripecias que vivieron los Aubrac durante el año 1943. Sin embargo, si nos ha interesado el caso, es porque es emblemático de las posturas que se entablan en la actualidad alrededor de la historia del tiempo presente, y que afectan al estatuto del testigo, al del historiador y a los usos ideológicos del pasado, por una parte, y porque muestra muy bien las difíciles y difusas relaciones entre la historia, la memoria, la justicia y los medios de comunicación. He aquí una serie de reflexiones que nacen del affaire Aubrac.

\section{LOS AUBRAC FRENTE A LOS HISTORIADORES}

\section{La mesa redonda}

El objetivo esencial de Raymond Aubrac durante la mesa redonda fue alcanzado. Todos los historiadores presentes afirmaton que la acusación de traición formulada por Jacques Vergès por cuenta de Klaus Barbie y más o menos validada por Gérard Chauvy era una infamia. Según Daniel Cordier, «los cinco bistoriadores presentes (Azéma, Bédarida, Douzou, Rousso, Veillon) reconocidos como los mejores especialistas de la Resistencia ban puesto en juego más que su carrera, su reputación, al pronunciarse unanimemente. Los Aubrac son inocentes sin reserva y sin matiz (...) De abora en adelante sólo los individuos de mala fe podran repetir basta la saciedad que los Aubrac ban sido traidores. Todos los ciudadanos están instruidos abora y saben que sois inocentes, gracias a la sola autoridad de cinco bistoriadores).

Sin embargo, como hemos visto, no todo fueron homenajes, ni mucho menos. Más bien todo lo contrario. Conforme iba pasando el tiempo, la mesa tedonda se transformaba en tribunal, al convertirse tres de los siete historiadores en «verdaderos inquisidorem, según Lucie Aubrac. En este sentido, incluso la palabra tribunal es un eufemismo. Raymond Aubrac dijo, con razón, que se trataba más bien de un «interrogatorio de policías. Nos parecen muy pertinentes las consideraciones de Jean-Pierre Vernant publicadas en un artículo titulado «Faut-il briser les idoles?» (Libération, 12-13 de julio de 1997): «Me ba parecido -sin que esté seguro de que esta impresión esté fundada- que los historiadores llegaban a manifestar respecto a los Aubrac una cierta hostilidad. (...) Los bistoriadores consideran que, si no la Resistencia, al menos la bistoria de la Resistencia es astmto de ellos. Les pertenece. Y miran de reojo a aquéllos que pretenden, fuera de ellos, por medio del relato de su experiencia personal, convertirse de algün modo en portavoces oficiales de lo que la Resistencia fues.

Hitonia, J.IX/3, num 203 (1299) 1105-1127 
Durante la celebración de la mesa redonda, frente a los Aubrac, los historiadores, convencidos de su autoridad y de su notoriedad, se convirtieron en acusadores que querrían hacerles confesar no se sabe muy bien qué. Daniel Cordier expresó crudamente su convicción de que Raymond ocultaba una cosas inconfesables y le preguntó, sin tapujos, qué era lo que disimulaba: «Yo sé que no disimulas unas traición, pero yo me pregunto sobre lo que intentas ocultar, por otro lado. Porque me parece que detrás de esta deriva, bay algo de inconfesable. Estoy triste por ello y por ello vuelvo a la carga: ¿qué disimulas?».

La única explicación que encuentra Raymond Aubrac para comprender este comportamiento es la fuerte tendencia a destruir un pretendido emito resistente». En este sentido, Henry Rousso, en un artículo titulado precisamente «De l'usage du mythe nécessaire" (Libération del 11 de julio de 1997) se pregunta: "L L verdad importa menos desde el momento en que se trata de "lucbar contra el fascismo", aire conocido desde los años 30 , o todavia de preservar unas figuras de las que nosotros tendríamos necesidad en gran medida, aire conocido desde los años 70 ? De 1971 a 1981 este argumento fue en efecto invocado al más alto nivel para justificar el recbazo a difundir en la televisión francesa "Le Chagrin et la pitié», de Marcel Opbuls, quien ponia en entredicho el mito de una Francia por completo levantada contra el invasor. Conocemos la continuación, y la inanidad de esta posición, cuando los franceses iban a emprender una inmersión dificil en las profundidades de su bistoria, de la que ellos no ban vuelto todavía. Es extraño, para alguien de mi generación, ver renacer asi el argumento del "mito necesario", que ha perjudicado tanto a la memoria nacional, y singularmente la de los resistentess.

Lo cierto es que la historia de la Resistencia no ha abandonado apenas las riberas de la epopeya conmemorativa y ha dependido más de la canción de gesta que de los análisis históricos más o menos racionales. El discurso de los "gtandes protagonistas» se ha erigido en historia "santa», monolítica e intocable porque competía, a los ojos del público, al dominio de lo sagrado. Como la Resistencia pertenece al patrimonio cultural de una mayoría de los franceses, que forma parte integrante de su herencia y de sus imágenes más nobles, que juega un papel en la construcción de su identidad nacional, podemos comprender la dificultad de escribir una historia crítica sobre tal tema.

Es evidente que el historiador debe de examinar todas las hipótesis y no debe haber para él ningún tabú. Pero desde huego no tiene el derecho de formular unas hipótesis sin ningún fundamento. Como ya hemos visto, Daniel Cordier pregunta a Lucie Aubrac si ella no ha sido involuntariamente tesponsable de la detención de sus suegros, los Samuel. Antoine Prost ha publicado un artículo de protesta (Le Monde, 12 de julio de 1997) titulado precisamente "Les historiens et les Aubrac: une question de trop». Nada, en los dossieres, permite establecer el menor lazo entre la detención de Aubrac y la de sus padres. Por otra parte, ninguno de los historiadores presentes en la mesa redonda ha aportado ninguna prueba en este sentido. Un testigo todavía vivo, detenido al mismo tiempo que los Samuel y transportado a Drancy al mismo tiempo que ellos, atestigua que ellos no fueron ni tan siquiera interrogados por la policía o la Gestapo después de su captura, lo que no habría sido el caso si esta hubiera tenido algún vínculo con un asunto relacionado con la Resistencia. La insinua-

/teptania, JIX/3, nim. 203(1999) 1105-1127 
ción es, por tanto, completamente gratuita. Y cuando el honor de un testigo o de un actor está en juego, el ejercicio legítimo de la duda metódica no debe sufrit, como asegura Prost, «la publicidad en tanto que la investigación no conduce a unas conclusiones claras, desprendidas de elementos recogidos después de una larga y paciente investigación, después de una bumilde y rigurosa confrontación con todas las fuentes disponibless. Antes de este esfuerzo de validación, las hipótesis y los documentos internos de trabajo deben permanecer en el secreto del gabinete del investigador. Sin estas precauciones de base, la duda ya no es metódica y el método se convierte en dudoso.

Se tiene todavía menos el derecho de pedir a aquellos de los que se sospecha de probar la inanidad de las sospechas que no se es capaz de justificar. Daniel Cordier pide a los Aubrac «demostran que la hipótesis gratuita es falsa. Queda claro que las reglas del derecho no son familiares a los historiadores. No solamente la lógica de posición ha conducido a algunos de ellos a transformar a los testigos en "acusados, sino que algunos han olvidado las reglas elementales del derecho penal al transferir sobre sus «acusados» la carga de la prueba de su inocencia. Antoine Prost encuentra ahí «una perversión: se franquea un limite ético, se atenta contra los derechos de la persona. Todo bombre tiene el derecho a ser respetado en lo que tiene de más bumano, y la piedad filial forma parte de ello. Todo bombre, incluidos los inmigrados, los vagabundos, los simples ciudadanos, e incluso los viejos. Incluso los resistentes). $Y$ es que nada autoriza a los historiadores a dar una legitimidad (sea la que sea) a la estrategia de la sospecha, a jugar, sin pruebas, con la dignidad de las mujeres y de los hombres que ellos encuentran y escuchan, a perjudicar a su "condición bumana», que es también la suya.

Por otra parte, Claire Andrieu y Diane de Bellescize (Le Monde, 17 de julio de 1997) han planteado dudas sobre la naturaleza de la mesa redonda como sistema de investigación. En efecto, la mesa redonda es un extraño sistema de trabajo que no proviene de ningún género porque los confunde a todos: ni instancia científica, ni dictamen pericial colectivo, ni comisión arbitral. La duración de la mesa redonda, un día, no se inscribía tampoco en la temporalidad de la investigación científica. Era demasiado larga o demasiado corta. Manteniendo una sesión durante cerca de seis horas, se exponían a franquear unas batretas psicológicas. Peto la jornada era demasiado breve también, ya que un año a tiempo completo bastaría a duras penas para volver a trazar de manera rigurosa el recorrido agitado de un antiguo resistente. Ni siquiera el lugar elegido para la reunión, la sede de un periódico, era el apropiado. Una sala de prensa en la que reina la urgencia no podía más que hacer recaer sobre la historia, disciplina lenta como toda ciencia, una obligación de resultado inmediato contrario a su naturaleza.

El riesgo era caer en una historia expeditiva que respondería más bien a los imperativos de la producción mediática. Precisamente, aunque el conocimiento histórico puede difundirse desde las salas de redacción de los periódicos, no puede construirse allí, no más que sobre los platós de televisión o en la sala de audiencias. Cada uno de estos lugares tiene su lógica de funcionamiento, que no es la de la investigación histórica. La separación de los lugares implica la se- 
paración de las funciones. Los historiadores no son ni periodistas, ni policías, ni jueces. Periodismo, justicia, policía e historia no tienen la misma relación con el tiempo, ni la misma relación con los hechos, ni los mismos métodos de análisis. La mezcla de los géneros mantiene la confusión e impide desempeñar convenientemente cada una de las funciones de las que la sociedad tiene necesidad. Esta confusión es muy curiosa, porque una vez que el asunto pasó de la sala de redacción de Libération a la sala de audiencias en la que se juzgaba por difamación a Gérard Chauvy, el periodista de Le Monde llegaba a escribir: «Raramente la oposición entre jueces e bistoriadores ha sido tan aguda. Defendiendo, el viernes 13 de febrero, a Raymond y Lucie Aubrac a quienes representa junto con Thierry Marembert, Georges Tiejman ba dado la impresión de defender los derechos de la sala de audiencias a resolver unos puntos de historia, tan bien, sino mejor, de lo que lo bacen los bistoriadores?".

El riesgo es, por tanto, grande, de confundir las exigencias científicas, los procedimientos judiciales y las necesidades mediáticas. La maquinaria de este modo construida abole la separación de las funciones y mezcla las reglas demostradas de cada profesión para retener algunas de ellas de manera aleatoria e inestable. Incluso sin intención precisa, el empleo renovado de este monstruo podría poner en funcionamiento unos fenómenos de dificil control.

\section{La Historia, entre la ilusión realista y el hechizo subjetivista}

En realidad, el problema es que en la cabeza de muchos historiadores se asocia la "memoria» con la «subjetividad», o sea, con la "duda», por un lado; y al «documento» con la "objetividad», es decir, con la «certeza», por el otro.

Es legítimo preguntarse sobre el estatuto de los escritos de los Aubrac: son tremendamente subjetivos. ¿En dónde situar, por ejemplo, el libro de Lucie, Ils partiront dans litrresse? Acogido unánimemente en el momento de su publicación por la crítica, incluidos algunos historiadores, la autora no ha dudado, sin embargo, en tomarse muchas libertades con el desarrollo de los hechos. No se trata de un estudio histórico stricto sensu, como reconoce Lucie Aubrac en el prefacio, sino de un relato: "He intentado bacer un relato tan exacto como sea posible en el tiempo y en los bechos. Me be ayudado para esto de mis propios recuerdos, de los de mi marido y de los testimonios de nuestros camaradas». Lucie critica a estos historiadores «reputados, serios, competentes en cuanto a la bistoria de la Segunda Guerra Mundiabs, que "llegan con su esquema de investigadores para delimitar del nodo más cercano la verdad bistórica. No abren más que una boja de la puerta de acceso a este extraordinario periodo, el que desemboca sobre las reglas tradicionales de estudio de una época con los becbos, las fechas, los análisis y las conclusiones que de éstos se desprenden, todo lo que bará un capitzlo o un libro bien arreglado, fuente autentica para uso do los curiosos y de los estudiantes. Estos historiadores son unos "investigadores", unos "especialistas" que entrojan la bistoria en su verdad desnuda y fría, lo que es necesarion. Sin embargo, ella, cuando explica a los

9 Sobre las dificiles relaciones entre la justicia y la historia, véase el libro de Carlo Ginz: в!nc, I/ giudice e lo storico, Turín, Einaudi, 1991, escrito poco después del priner proceso Sofri.

Nitpaniu, I.IX/3, núrn. 203 (1999) 1105-1127 
jóvenes su pasado de resistente, lo hace del siguiente modo: «No tomo el desarrollo evenemencial de su libro de bistoria. Yo llego con unos posters, unos periódicos clandestinos, una estrella amarilla, unas cartas de fusilados, unas bistorias insensatas a menudo borrorosas en el recorrido de los resistentes. Me convierto para estos jóvenes en la narradora de una época que sólo aquellos y aquellas que la ban vivido pueden bacer comprendern.

Raymond Aubrac reconoce que tampoco ha hecho un trabajo de historiador, sino una reseña de actividad que va desde su infancia hasta los años 80 . Indica en el prólogo de Où la mémoire s'attarde: «A veces be podido tomar algunas notas, cuando las circunstancias me parecian importantes y tenía tiempo. He conservado las pequeñas agendas en las que anotaba mis citas y mis viajes. Pero estas agendas, que tengo desde 1934, están vacías entre 1940 y 1944, cuando bacia falta memorizar, no babria por qué extrañarsè.

Sin embargo los profesionales de la Historia trabajan por lo general de otra manera. Existe una idea, enraizada en la mentaiidad de muchos historiadores, según la cual cada autor o cada escuela han conseguido describir la «realidad bistónicos) en su totalidad tal y como ocurrió (wie es ist eigentlich gewesen, en palabras de Ranke). No cabe duda de que también son conscientes de que quizá no estén describiendo toda la realidad, pero de lo que por el contrario, no dudan es de que, si bien es cierto que no nos están contando todo, por lo menos sí lo es el que nos cuentan lo que es verdaderamente importante, aquello que nos permite comprender toda la realidad porque es el mecanismo oculto que la rige. Ya sea aspirando a lograr una Historia total, o conformándose con descripciones de la realidad histórica mucho más limitada, en cualquier caso los historiadores siguen compartiendo la misma ilusión: nos ofrecen retazos de la realidad o la realidad absoluta, según sus pretensiones. La Historiografía europea, tal y como se configura a partir del siglo XIX pasará a considerar al texto, al documento histórico, como la única base sobre la que es posible construir un discurso historiográfico, obviando toda la compleja serie de operaciones que van desde la fijación de un texto histórico como fuente hasta su lectura e interpretación. No cabe duda de que el historiador conoce perfectamente todos y cada uno de los pasos a seguir en la producción de un texto historiográfico; quizá no los formule con la nitidez de un manual de método, pero sí que los practica y se va ejercitando en su uso a través de un proceso de aprendizaje en el que adquiere toda la serie de destrezas que le permitirán ejercer su oficio. Si decide obviar, en cierto modo, su existencia es porque cree que todos esos pasos no son más que un medio que le permite tener un acceso directo al pasado. Respecto a la consideración del testimonio oral como documento, lo cierto es que las dificultades de interpretación aumentan de tal modo que, como Dominique Veillon aconseja, «la confrontación entre testimonio y documento se revela más que nunca indispensables.

Esta confianza ciega en la historia, el método histótico y el documento (en detrimento, por norma general, del testimonio) para descubrir (da verdad» caracteriza a la gran mayoría de los historiadores que asistieron a la mesa redonda. Es particularmente evidente en el caso de Daniel Cordier, para quien, además, la exclusividad del descubrimiento de sh verdad histótica» pertenecería a los profesionales de la historia: "en el plano de la Historia -el que nos interesa porque es el de la posteridact so- 
lamente los historiadores están habilitados para investigar la verdad y decirla. Su formación, su erudición, su estatuto les confieren una autoridad científica (al mismo tiempo que una autoridad moral) incomparable para establecer la verdad bistórica y traer aparejada la adbesióms. De ahí la importancia fundamental concedida a los documentos: «la dificultad mayor de vuestro «affaire» (...) reside en la ausencia de documentos alemanes no permitiendo actualmente responder a esta acusación apoyándose sobre unas pruebas irrefutabless. Es más, acusa a los Aubrac porque por culpa de sus contradicciones los historiadores tienen problemas para conocer esta verdad: «La verdad del pasado, que parece siempre dificil de detectar en la juntura delicada y decisiva entre los documentos y Los testimonios, es en este caso difficil de establecer a causa de la ausencia de documentos y de los extravios de vuestros testimonios. Y esto, en el momento en el que los historiadores babrian tenido tanta necesidad de testimonios irrecusables. i $E$ s a causa del carácter particular del problema que vuestras fintas, vuestros embellecimientos, vuestras contradicciones, os ponen en una situación delicadasis.

Henry Rousso también asegura que «cuando [Lucie Aubrac] nos dice boy que ba tomado unas libertades con los bechos, se siente un singular malestar, no porque nosotros la bayamos creido (equivocadamente, parece decirnos boy), sino porque parece de este modo renegar de la posición que ba adoptado siempre, a saber, defender la importancia crucial de la memoria de los actores como escritura veridica de la Historias.

Pero sin duda, el abanderado de esta historia "wie es ist eigentlich gewesen es François Bédarida. En primer lugar, critica duramente la actitud de Lucie y Raymond Aubrac: «...por estar erigida en paradigma de la memoria nacional, la Resistencia no tiene necesidad ni de ser "arreglada" por unos relatos más o menos novelados, ni de ser oscurecida por las versiones flotantes de los actores, ni beroizada por unas personificaciones inevitablemente temporales. Por el contrario, tiene necesidad de todo el rigor del método bistórico, lo que exige tanto la empatía como el espiritu crítico, guardándose por encima de todo de las aproximaciones y de las reconstrucciones retrospectivass. En un articulo titulado precisamente «Mémoire de la Résistance et devoir de vérité» (Libération, 12-13 de julio de 1997), Bédarida asegura que «es un becho que, por su propia naturaleza, la Resistencia está sujeta a la heroicización.(..) De abi el combate tenaz e ingrato conducido por los bistoriadores contra las deformaciones y las mitificaciones. (...) Es a este precio al que se transmitirá y se perpetuará la verdadera imagen de la Resistencia. Una cosa es segura: una política de la memoria no puede reposar más que sobre una obra de verdad. Está a hí también el medio de evitar las esquematizaciones simplistas, las aproximaciones abusivas. (...) El verdadero trabajo, y el único, consiste en restituir pacientemente la cadena de la verdad. $Y$ de observar la buena vieja regla enunciada por Charles Péguy bace un siglo: "Decir la verdad, toda la verdad, nada más que la verdad, decir tontamente la verdad tonta, aburridamente la verdad aburrida, tristemente la verdad tristes).

¿Cómo se configura la realidad histórica, si queremos abandonar de una vez por todas la ilusión realista y si no queremos dejarnos embriagar por la más pura subjetividad? No tiene sentido una vuelta attás, puesto que el realismo ingenuo resulta totalmente insostenible. Deberemos admitir que en Historia la realidad se construye porque en la producción de la obra historiográfica tienen efectivamente lugar una serie de procesos mediante los cuales se elaboran los documentos, se configuran los acontecimientos y se impone un sentido al devenir histótico.

Ilijpuntu, LIX/3, núm. 203 (1999) 1105-1127 
Hay técnicas para hacer todo ello, podemos verlas en funcionamiento, e incluso manejarlas, pero todas ellas trabajan sobre un sustrato previo: la construcción de un documento es algo distinto a su falsificación, y no es lo mismo elaborar un acontecimiento historiográfico que inventárselo, $\mathrm{y}$, por supuesto, sólo algunos sentidos son posibles en un proceso histórico, y no cualquier sentido.

También es posible salir de la cátcel de la subjetividad. Pero para ello no debemos volver a modelos anticuados que niegan su existencia y a creernos conocedores de la realidad misma, olvidando que eso que llamamos realidad es un constructo. El camino a seguir, por el contrario, no será una marcha hacia atrás, sino un avance hacia adelante. Debemos partir de que la realidad se construye social e históricamente, de que el sujeto desempeña un papel fundamental en el proceso de conocimiento y de que el historiador utiliza, en efecto, numerosos medios expresivos que pueden ser cbjeto de un análisis retórico.

No existe el conocimiento sin el sujeto, de la misma manera que tampoco habría Historia si no hubiesen historiadores. Pero tampoco es posible el conocimiento si no hay objeto a conocer y los historiadores no tendrian nada que decir si no existiese un correlato objetivo sobre el que desarrollar sus discursos. Como explica José Carlos Bermejo Barrera, «lo que ocurre es que siempre quedará un resto que es imposible conocer, a lo que Kant gustaba llamar "cosa en si". En Historia el conocimiento absoluto del pasado es una mera ficción, la Historia total es una vana ilusión, que, por otra parte, siempre ba sido consciente de sus limitacioness ${ }^{10}$. El objeto de estudio de la Historia lo serían hipotéticamente todos los hombres que han vivido en el pasado, además del problema de sus orígenes, y todo lo que les pudo haber ocurrido a todos y cada uno de ellos en cada momento, ya que nadie puede negar la importancia a un acontecimiento que no conoce, pues no sería ni prudente ni cientifico.

A todos estos historiadores obsesionados con la realidad bistórica, hay que recordarles las palabras siempre acertadas de Jean-Pierre Vernant, al término de la mesa redonda: «Quedan dos cuestiones subsidiarias que suponen un problema y sobre las cuales Raymond Aubrac responde: «No sé». ¿Hay que sorprenderse? La experiencia me ba enseñado que en el transcurso de los acontecimientos históricos, en el comportamiento de los bombres, e incluso, en lo que concierne a cada uno de nosotros, en sus motivaciones, existen unas preguntas que se plantean, incluidas sobre nosotros mismos, sin poder resolver, $y$ en donde la respuesta es: no sés.

10 José Carlos Bermejo Barrera, Entre Historia y Filosofia, Madrid, Akal, 1994, p. 215. Sobre todas estas consideraciones en torno a la naturaleza del documento, el acontecimiento, el conocimiento y el método históricos, véase especialmente, de este autor, Fundamentación lógica de la bistoria, Madrid, Akal, 1991. 